Bol. Acad. peru. leng. 47. 2009 (27-53)

\title{
ABORDAJE DIACRÓNICO DE LOS MECANISMOS DE CITACIÓN Y DE EJEMPLIFICACIÓN EN LA LEXICOGRAFÍA DIFERENCIAL CUBANA
}

\author{
APPROCHE DIACHRONIQUE DES MÉCANISMES DE \\ LA CITATION ET DE L'EXEMPLIFICATION DANS LA \\ LEXICOGRAPHIE DIFFÉRENTIELLE CUBAINE
}

\section{DIACHRONIC TREATMENT OF THE MECHANISMS USED IN CITATION AND EXEMPLIFICATION IN CUBAN DIFFERENTIAL LEXICOGRAPHY}

\author{
Aurora M. Camacho Barreiro
}

Resumen:

Este estudio se propone abordar la problemática de la citación y la ejemplificación en la lexicografía cubana a través de su larga trayectoria, de tal manera que la inclusión o no de las citas y de los ejemplos en la microestructura de los diccionarios diferenciales cubanos, los mecanismos seleccionados por los diccionaristas -léase, empleo de citas o creación de los ejemplos-, su tratamiento tipográfico y la presencia del componente ideológico en ellos serán los objetivos específicos de esta investigación, que por otra parte tributa de forma sustancial a la tesis doctoral en curso.

Résumé:

Cette étude propose d'aborder la problématique de la citation et de l'exemplification dans la lexicographie cubaine à travers sa longue trajectoire, de sorte que l'inclusion ou non des citations et des exemples 
dans la microstructure des dictionnaires différentiels cubains, les mécanismes sélectionnés par les lexicographes -voir emploi des citations ou création des exemples-, son traitement typographique, ainsi que la présence de l'élément idéologique dans ceux-ci constitueront les objectifs spécifiques de cette recherche qui, d'autre part, reprend substantiellement la thèse de doctorat en cours.

\section{Abstract:}

Problems in the system of citation and exemplification in Cuban lexicography such as inclusion or rejection of cites and examples, the mechanisms for their selection, their typographic handling and the actual presence of an ideological component are the matters to be treated in this article.

Palabras clave:

Lexicografía; Cuba; diccionarios; microestructura; cita.

Mots clés:

Lexicographie; Cuba; dictionnaires; microstructures; citation.

Key words:

Lexicography; Cuba; dictionaries; microstructure; cites.

Este artículo se propone abordar la problemática de la citación y la ejemplificación en la lexicografía cubana a través de su larga trayectoria, de tal manera que la inclusión o no de las citas y de los ejemplos en la microestructura de los diccionarios diferenciales cubanos, los mecanismos seleccionados por los diccionaristas -léase, empleo de citas o creación de los ejemplos-, su tratamiento tipográfico y la presencia del componente ideológico en ellos serán los objetivos específicos de esta investigación, que por otra parte tributa de forma sustancial a la tesis doctoral en curso. En consecuencia se han incluido los mismos repertorios de palabras que en otros estudios preliminares, como es el caso del más reciente trabajo: "Las marcas sociolingüísticas en una muestra de la lexicografía cubana: tipología y evolución” (en vías de publicación en la 
Revista de Lexicografía, de la Universidad de la Coruña) con vistas a lograr una muestra lo más homogénea posible. ${ }^{1}$

Debemos distinguir en primer lugar que existen dos mecanismos fundamentales para que el lexicógrafo ilustre el uso de una determinada palabra o lema. Con este propósito debe elegir entre los ejemplos o las citas -también llamadas autoridades- tomadas de los textos escritos. Los ejemplos son creados por los diccionaristas, a libre elección y estilo y tal como ha advertido Eulalia Lledó "[...] son palabras en vivo, desde el momento en que son un trocito de vida, (y) adoptan las formas más variadas según quiera ilustrarse un concepto u otro, [...]", quieren ser "una pastilla concentrada de lengua real" $(2004: 225)^{2}$ y son asimismo un constructo modélico de la realidad, de tal manera que no escapan entonces a la carga (o descarga) ideológica, como veremos a continuación.

Para José Álvaro Porto Dapena, esos textos inventados por el propio lexicógrafo, "pierden su calidad de "autoridades" para convertirse en meros ejemplos, a veces muy apropiados y útiles" (2002:194).

Las citas o autoridades, por otra parte, son escogidas por los diccionaristas de entre la literatura u otras fuentes, y en su selección también emerge cierto condicionamiento, ciertas preferencias y por demás, revelan también un posicionamiento ideológico. Por diccionario de citas se entiende - precisa Porto Dapena- "el que utiliza como ejemplos o autoridades pasajes de textos escritos” (Id.:65), que se convertirán asimismo en un sancionador del uso y no en un simple ejemplo (Id.: 107).

1 Con riesgo - por supuesto- de dejar fuera otros diccionarios, glosarios o enciclopedias que registran la modalidad cubana del español de antaño o de fechas más recientes o incluso repertorios como el Diccionario básico escolar (2005), del Centro de Lingüística Aplicada, de Santiago de Cuba o el Breve diccionario de la lengua española (2006), del Instituto de Literatura y Lingüistica, que por su orientación específica como diccionarios escolares exigen otro abordaje metalexicográfico.

2 A esta autora debemos un detallado y cuidadoso estudio sobre la presencia femenina en la edición del XXII DRAE que se integra al volumen Mujeres y diccionarios. Evolución de lo femenino ..., 2004. 
"Los ejemplos, bien se deban al mismo lexicógrafo o al equipo lexicográfico que redacta el diccionario, bien se hayan extraído de algún corpus, se aducen esencialmente para facilitar el uso de la palabra [...]" (49), advierte Elena Bajo López en un epígrafe dedicado al tema en su obra Diccionarios. Introducción a la historia de la lexicografía (2000), objetivo que a su juicio requiere "mucho esfuerzo y considerable intuición idiomática". Criterios de aplicación de gran actualidad, profundidad de análisis y un dominio exhaustivo de la materia son algunas de las características de este documentado estudio, que por otra parte entra de lleno en la polémica acerca de la pretendida neutralidad de la ejemplificación en los repertorios de palabras: "Los ejemplos, sin duda, suponen un enriquecimiento muy notable del diccionario, pero conllevan también un riesgo: revelan mucho sobre la mentalidad de quien los elige, todavía más y de forma no menos sutil que las propias definiciones, [...]" (Subrayado ACB, 51). La ausencia de citas o autoridades y de ejemplos puede empobrecer el repertorio, y puede asegurarse que no es ese el camino para atenuar la carga subjetiva que ellos vehiculan. La funcionalidad de unos y otros queda demostrada a través de la historia de la lexicografía hispánica. Bajo López llega a afirmar, incluso, que "cuanto más frío resulta un ejemplo, menos interés provoca" (51), interesante punto de vista que, junto a la pretendida neutralidad y la objetividad en lexicografía, son aspectos a dilucidar. No cabe duda de que un ejemplo creado por el lexicógrafo despierta mayor interés y funciona mejor en su condición de ilustrador de un uso determinado si en su construcción se emplean elementos y situaciones tomadas de una realidad sociohistórica concreta en las que el usuario se vea reflejado. Todo ello supone, sin embargo, una contradicción: ¿cómo establecer una conexión con un determinado entramado histórico y social y conseguir esa neutralidad a la que debe aspirar el texto lexicográfico? Todo parece indicar que en la propia elección de las citas o en la elaboración personal de los lexicógrafos de algún ejemplo ya estamos en presencia de elementos subjetivos, personales y en su extensión, sociales; aunque todo ello se produzca de manera más o menos sutil, más o menos consciente.

No nos parece, con Esther Forgas (2004:2), que puedan establecerse verdaderas diferencias en cuanto a los contenidos ideológicos vehiculados a través de los ejemplos creados y los tomados de diversas fuentes o citas. 
En todos ellos está presente la selección personal, la visión e interpretación del mundo del lexicógrafo y aun de los equipos de trabajo más modernos: una selección que pocas veces logra despojarse del todo de una toma de partido en torno a aspectos tan disímiles como la moral, la sexualidad, la religión, la cultura, la política o la propia lengua. Sobre el Diccionario de la lengua catalana, de Pompeu Fabra comenta Forgas que "[...] els exemples no fan res més que reflectir un estat de coses, a més d un estat d 'opinió" (324).

Forgas, por otra parte, precisa que si bien es cierto que "en muchas ocasiones, para la elaboración del ejemplo lexicográfico no se ha partido necesariamente de una intencionalidad previa, didáctica, moralizadora o ideologizante" (2004:3), no evita, pues no se lo propone ni podría, ilustrar además acerca del "estereotipo de uso, el concepto manido, la apreciación generalizada”. Esta autora asevera que la mayoría de las veces el ejemplo lexicográfico "lo es a voluntad", pues responde a una intención ideologizadora -o ideologizante- dentro del contexto de una sociedad dada. En su estudio sobre tres décadas de la sociedad española -entre los años 70 y los 90 del siglo XX- a través de los ejemplos lexicográficos demuestra de forma fehaciente que en ellos se vuelcan trozos de vida, como queda corroborado en las referencias a las mujeres españolas y su proyección social, su incorporación al trabajo, la ascensión de la democracia, el avance tecnológico, entre otros aspectos no menos esenciales. La investigadora propone una suerte de término medio entre el ejemplo no comprometido y el marcadamente partidista, que propicie un margen de operatividad e independencia creativa al lexicógrafo. En otra aproximación suya al fenómeno rastrea la imagen social que de la mujer española transmiten los diccionarios españoles: aspecto físico y condiciones morales, edades de la mujer, profesiones y oficios, sus roles familiares y con respecto al hombre, entre otros temas.

Otros estudios abordan también esta problemática de los ejemplos desde la perspectiva morfosintáctica en la lexicografía en lengua española, que es la que nos ocupa de manera especial, por su incidencia en la producción de diccionarios en América, y en particular en Cuba. Manuel Alvar Ezquerra en su imprescindible Lexicografía descriptiva (1993) propone 
una revisión que nace con el Diccionario de Autoridades y repasa otras piezas claves de la lexicografía en España en cuanto al estudio del aspecto sintáctico de los ejemplos, aspecto que como señala ha motivado menos a los estudiosos sobre el tema que su vertiente semasiológica. El autor se detiene a especificar de qué manera dichos repertorios ejemplifican según se trate de un sustantivo, un adjetivo, un verbo, un adverbio, un pronombre, una preposición o una conjunción. El diccionario -dice Alvar Ezquerra- no sólo proporciona información acerca de cuestiones morforsintácticas sino también sobre elementos de naturaleza semántica. En lo tocante a la problemática ideológica es categórico al afirmar que "[...] es en los ejemplos donde la ideología, la situación sociocultural, se manifiesta más claramente" (1993:137). Alvar Ezquerra también revisa la forma de presentación de los ejemplos y repara en el hecho de que algunos lexicógrafos no hacen uso de tipografía diferenciada, de tal manera que no propician su rápida y fácil localización.

María Bargalló desde su condición de gramatóloga también ha atendido la función sintagmática del ejemplo lexicográfico y su abordaje metalingüístico en los diccionarios monolingües (2002, 2007).

Carmen Delia Valadez (2006) ofrece, por otra parte, un pormenorizado recuento acerca del tratamiento de los ejemplos en el Diccionario del Español Usual de México. Cada vocablo - dice- va marcando el tipo de ejemplo pertinente, es decir, de acuerdo con la clase de palabra así se construirá ese "puente" que acerca "la lengua al hablante de todos los días, [...]" (162) y que nos ofrece elementos descriptivos acerca de su uso. Una visión del fenómeno desde la óptica y criterios metodológicos de los diccionarios integrales, según la perspectiva teórica de Luis F. Lara y discípulos.

Una vez revisados algunos aspectos metalexicográficos en torno al tema en cuestión, parece oportuno echar un vistazo al fenómeno en la muestra de diccionarios diferenciales seleccionados y dejar establecidos los principales aspectos a considerar:

- preferencia por las citas o autoridades o por los ejemplos creados, - alternancia del uso de citas y de los ejemplos creados, 
- tratamiento tipográfico,

- modos de presentación en el artículo lexicográfico,

- y tendencias identificadas en la lexicografía diferencial del español de Cuba.

\section{Análisis de la muestra}

El subrayado de los ejemplos creados o citados es nuestro. Los ejemplos se han delimitado con rigurosidad, dada la abundante y heterogénea información que contienen una buena parte de los artículos lexicográficos y la irregular disposición de la citación y de la ejemplificación. En aquellos casos en los que la información volcada en el artículo lexicográfico es muy extensa y no aporta elementos en la dirección de nuestra indagación la hemos suprimido y marcado entre paréntesis. Esto ocurrirá en numerosos casos, pues es sabido que los lexicógrafos cubanos trasladan a sus repertorios de palabras abundantes comentarios sobre disímiles aspectos que si bien requieren atención y análisis no se corresponden con los objetivos de este artículo.

El primero de los diccionarios de provincialismos y uno de los mejores del siglo XIX, al decir de Haensch (1994: 49), sale publicado en 1836 y posteriormente Esteban Pichardo, geógrafo de profesión, lo reedita en 1849 , en 1861-62 y en 1875, como respuesta a modificaciones de orden conceptual que quedan plasmadas en sus respectivos títulos. Representa, además, una corriente que censuró las voces americanas, al separar a manera de suplemento las llamadas "corruptelas" muy a tono con un sentimiento de autodiscriminación o de autocensura que predominara entonces. En el Diccionario provincial ..., E. Pichardo en sus cuatro ediciones (la revisada es 1976) emplea ejemplos solamente en las entradas de agua, aquel, carabela, caringa, cruz, chancleta y pechicato. Todos son de su inventiva. Veamos:

agua: Generalmente usa el vulgo esta palabra por término de comparación de suma abundancia, verdad o evidencia. "Había más gente que agua" o "había gente como agua". "Esto está claro como agua". 
aquel: El vulgo ínfimo suele usar esta palabra como nombre sustantivo agregando una o para significar que tal persona posee cualidades o circunstancias que no se pueden o se saben explicar. "Fulano tiene un aquel". "Zutano con su aquel". [...]

carabela: Palabra muy usada entre los Negros Bozales algo ladinos, significando el paisano que vino de Guinea en un mismo buque. "Fulano carabela mío". [...]

caringa: Canción usada por la gentualla y que suele bailarse también. “Toma, toma y toma, caringa a los viejos pelo y jeringa”.

cruz: Hacer la cruz. Frase vulgar de los caleseros de alquiler y vendedores por las calles de La Habana para significar la primera peseta o moneda que reciben en el día como producto de su tráfico, persignándose o haciendo la cruz con ella. Así dicen "todavía no he hecho la cruz”, ningún viaje, nada he vendido aún.

chancleta: Sinónimo de chinela y pantufla pero tenga o no orejas y talón el zapato, con tal que este se doble y pise con el calcañal; [...]: "es un chancleta o una chancleta".

pechicato: Miserable, cicatero. En la parte Occidental es muy usado, gritando los muchachos al padrino o madrina de bautismo con este adjetivo cuando no reparte monedas.[...] Si el padrino se incomoda y los quiere ahuyentar sin darles medios, entonces se dispersan "Huye Pepe que te coge Tondá" y empieza la gritería de lejos "Padrino pechicato”.

Los ejemplos creados aparecen a continuación de la definición, precedidos por punto o por dos puntos, entrecomillados y de manera general dispuestos al final del artículo lexicográfico, aunque también los intercala, como ocurre con aquel. No cita a ninguna autoridad. La ejemplificación proporciona también información sintagmática, como ocurre en "Esto está claro como agua" o "Es un chancleta o una chancleta", en los que aparece la combinatoria de la locución "estar claro, 
a" o se precisan aspectos gramaticales sobre el género, indistintamente. Reproduce, incluso, el modo de hablar característico del africano trasplantado a tierra cubana, como en carabela, en la que no se refleja la forma verbal. La ejemplificación es escasa. Nuestro primer lexicógrafo privilegia la definición y a pesar de que también abunda en información suplementaria en un diccionario de lengua no recurre a la ejemplificación por invención o por citación de forma significativa: esta última modalidad, incluso, no aparece en el repertorio, como ya quedó expresado.

La aportación lexicográfica de Constantino Suárez, alias "El Españolito" no ha sido muy estudiada en Cuba, sin embargo su recopilación de voces es muy valiosa. Su condición de extranjero y sus motivaciones nos llevaron a considerarlo en la investigación sobre el entramado ideológico que subyace en los diccionarios nacionales. En el Vocabulario cubano, Suárez (1921) utiliza ejemplos creados en las entradas barrigón, basurita, beneficiar, botija verde, brisa, cañón, chirigotero, chivo, choteo, cogioca, desguasar, embarrilar, gallina, indigestarse, indomia, montón - pila, negrero y rosario. Veamos:

barrigón: Dícese a los hijos de corta edad, como indicando que todas las actividades de ellos están en la barriga: "Tengo tres barrigones"; "voy a comprar dulces para los barrigones".

basurita: Comúnmente sustituye a la palabra "propina" en el sentido de pequeña dádiva; y otras veces equivale a "un poco más" cuando se pide algo de lo que se desea. "Siempre doy al barbero una basurita". "Eso es poco; deme una basurita más".

beneficiar: Matar una res para el consumo de su carne. "Pues eso mismo - dijo Liborio- he observado cada vez que en la hacienda beneficio una res". [...]

botija verde: Término de comparación el más ofensivo, cuando se alude a los insultos que ha merecido o puede merecer una persona. [...] "Le dije hasta botija verde y no se dio por ofendido". 
brisa: Así dice la gente del pueblo, no sin cierto gracejo, en vez de apetito: "Tengo brisa; voy a meterme la frita”. [...]

cañón: Aplícase como en sumo grado ponderativo a una cosa que satisface todos los deseos del gusto. [...]: "Eso está cañón"

chirigotero, ra: Se aplica a la persona muy aficionada a mezclar chirigotas (España; Andalucía) o cuchufletas en su conversación. "Diego es un chirigotero poco oportuno".

chivo: Negocio sucio, ilícito, particularmente si lo efectúa algún político: "El senador H. entra en todas clase de chivos".

choteo: Burla, broma de palabra. Algunos dicen "choteadera", cuando más bien se trata de una tomadura de pelo. "Déjate de choteos y vamos a tratar el asunto seriamente". "Al actor tal le formaron la gran choteadera, porque se equivocó en un verso”. [...]

cogioca: Significa el afán de lucro en algunos políticos que solo persiguen el medio personal. "Zutano dice que se sacrifica por la Patria, pero le gusta mucho la cogioca”.

desguasar: [...] Se usa en su acepción marítima, pero se extiende a todo acto en que destroza o desbarata una cosa con algo de violencia: "La niña desguasó la muñeca", "algo se desguasó en la cocina”.

embarrilar: Se oye en boca de la plebe, dándole significado de "matar", y lo ponen en ejecución los barateros cuando por casualidad son homicidas: "Ese embarrila a cualquiera"; "No te metas con ese, porque te embarrilará".

gallina: Suele sustituir a la palabra "mujer", cuando se trata de enaltecer las gracias físicas de ella y así se dice: “¡Vaya una gallina!”; "la gran gallina". 
indigestarse: Metafóricamente se indigesta el que no comprende o no digiere ciertas lecturas: "Juan se indigestó con lecturas anarquistas, y de tanto oírle disparatar”.

indomia: Entre gente campesina significa novedad, modernismo: "A mí que no vengan con indomias, porque no hay más verdades que las legadas por nuestros padres", dice un campesino.

montón - pila: Ridículo pleonasmo para denotar mucha abundancia de algo: "Tiene montón - pila de dinero".

negrero: Aplícase al hombre blanco aficionado a enamorar mujeres negras: "Dicen que los catalanes son muy negreros". [...]

rosario: Entre gente rústica, pero con gracejo indiscutible, se oye esta voz como para significar término o frase confusos por la novedad; [...]: “-iQué rosarios son esos de que está Ud. Hablando, señor Conde?-” esto dice Liborio en la página 92 de Aventuras de un Mayoral, por Don Juan R. Giménez. [...]

Los ejemplos se presentan a continuación de la definición o de las correspondientes acepciones - precedidos en nueve casos de dos puntos y en los restantes artículos de punto y seguido-, entrecomillados, situados de manera general al final del artículo lexicográfico, aunque alterna esta colocación con su presentación intercalada. Suárez recurre de forma irregular a uno o dos ejemplos de su inventiva y en los lemas beneficiar e indomia se vale del discurso directo puesto en boca de personajes distintivos de lo cubano al utilizar mecanismos de citación tales como "-dijo Liborio" y "-dice un campesino", de tal manera que introduce un modelo de ejemplificación novedoso. Solamente cita una autoridad al definir rosario, donde refiere "esto dice Liborio en la página 92 de Aventuras de un Mayoral, por Don Juan R. Giménez". Sobre esta referencia hemos indagado y encontramos algunas imprecisiones debidas al propio Suárez o a la edición correspondiente, pero que conviene aclarar: en el repertorio se cita a Juan R. Giménez como autor de la obra Aventuras de un mayoral, pero en realidad se trata de Juan Bautista Jiménez que publicara 
dicha obra en $1882 .{ }^{3}$ Un apunte necesario sobre una errata que conviene corregir, sobre todo si se tiene en consideración que es la única cita de autor en todo el Vocabulario....

Además, Suárez ofrece información complementaria acerca de la combinatoria verbal y otros elementos de naturaleza sintagmática, en casos tales como "Le dije hasta botija verde...", al definir botija verde y precisar que se construye con el verbo decir o en cogioca, donde proporciona información de tipo gramatical sobre el género al presentar el ejemplo "[...] le gusta mucho la cogioca". En la ejemplificación del lema choteo, Suárez se equivoca y emplea en uno de los dos ejemplos de su inventiva una derivada del vocablo definido (choteadera).

La alusión a la corrupción reinante en el país se advierte en la ilustración del uso de voces tales como chivo y cogioca, fenómenos muy extendidos en la República neocolonial, y que los lexicógrafos en Cuba no pasaron por alto, como quedó demostrado en otra aproximación a la presencia del componente ideológico en los diccionarios cubanos (Camacho, 2003-2004:21-38). Ciertos matices androcéntricos podrían atribuirse a un enunciado ejemplificador como "La niña desguasó la muñeca" o "algo se desguasó en la cocina", en los que resulta más que sospechosa la elección del agente de la acción descrita (v. desguasar) y el ámbito de su realización, la cocina. Otro asunto no menos cargado de ideología se aprecia en su comentario racista acerca de la preferencia sexual de los catalanes por las mujeres de raza negra (v. negrero), opinión que revela también, por supuesto, un trasfondo socioclasista: no pueden ignorarse las diferencias entre las diversas nacionalidades procedentes de España y establecidas en Cuba desde la conquista y colonización. El ejemplo vehicula un estado de ánimo y una actitud de clase: Constantino Suárez es de origen asturiano, por otra parte, y no logra sustraerse de cierto condicionamiento ideológico en el abordaje de algunos temas.

3 Libro que consta de dos volúmenes y aborda asuntos relacionados con la agricultura y la ganadería: cultivos menores, pastos y prados artificiales, la caña de azúcar, etc. 
En el Nuevo Catauro de Cubanismos (1985), obra póstuma en la que Ortiz amplía, enmienda y enriquece Un catauro de cubanismos, de 1923, registra 2369 entradas de las cuales cincuenta y cinco son denominaciones agrupadas o combinaciones de palabras. En esta renovada versión el sabio cubano distingue con marca gramatical a cincuenta y ocho lemas, lo cual es un indicativo de la relevancia que le concede a la información sobre las clases de palabras desde el punto de vista gramatical. En este repertorio presenta ejemplos en las entradas de acá, acartonar, aletear, aplazado, caída, cajón (de), catedrático, chirimoya, contado rabioso (al), diablito, empleomanía, fajar, forro, garete, guasasa, guerrita, morenaje, rabo, reales y rosita. Veamos:

acá: Se usa este adverbio vulgarmente, como pronombre: "Acá me dijo". [...]

acartonar: No solamente se dice, como el diccionario de la R. A., de la persona de edad, quedarse enjuta, pero sana; sino, también por analogía del enfermo o tísico al quedarse enjuto y aparentemente curado. "Fulano está encartonado".

aletear: Vulgarismo. Estar en la inopia. [...] "Fulano está aleteando".

aplazado, a: Unido en concubinato, con promesa de matrimonio aplazado. Es voz de Oriente, según Ramón Martínez. ¡Honesto eufemismo! "Vivían aplazados". [...]

caída: Cierto contoneo gracioso al caminar o movimiento picaresco en la mímica. "Ella tiene una caidita de aronga". "Tiene una caída de ojos".

cajón: No siempre es en Cuba aumentativo de caja, pues a la cajita de tabacos se le suele decir siempre cajón. [...] De cajón es "de veras" o "con seguridad". "Iré a verte mañana de cajón". "Debemos pagar eso de cajón”.

catedrático: Intelectualmente petulante. Estilo que ridiculiza a los catedráticos. "Es un negrito catedrático". 
chirimoya: Bien definida por la Academia, que adopta plenamente ese vocablo. Suele usarse en Cuba, vulgarmente, como sinónimo de cabeza. "Le cayó la teja sobre la chirimoya". [...]

contado rabioso: Suárez explica atinadamente esta locución. "Equivale a decir sencillamente: al contado; y si familiarmente se añade rabioso es por dar más fuerza a la expresión, pero no la tiene el efecto: "Yo pago siempre al contado rabioso". [...]

diablito: Suárez da una explicación aproximada pero se equivoca cuando supone que la comparsa el diablito, es siempre comparsa de ñáñigos. Los ñáñigos tienen su diablito ireme; pero no todos los diablitos eran ñáñigos. Diablito fue todo negro africano vestido a usanza de su tierra o chabacanamente, que el día de Reyes o con motivo de otras festividades, salía a la calle a bailar y refocilarse con sus paisanos y compañeros de servidumbre. En nuestro estudio acerca de la fiesta afrocubana del día de Reyes, escribíamos: “¿Por qué a esta fiesta se llamó de diablitos? Acaso porque al tener que darle nombre los blancos, encontraron en los disfraces abigarrados de los africanos en sus saltos y cabriolas, en sus cuernos y caretas, cierta analogía con los diablitos o diablillos, [...]

empleomanía: Conjunto de empleados. "Redujo la empleomanía de la casa”. [...]

fajar: Acometer con violencia, embestir con respecto a los animales: "Un perro que faja". Se usa también con la significación de enamorar: "Juan le está fajando a Rosa". [...]

forro: Suárez expone la vulgar acepción común: "trampa, engaño". [...]. En el lenguaje de los politiqueros, es el falso elector y el voto ilegalmente emitido o el simulado en las actas de escrutinio. "El concejal salió gracias a sus muchos forros”. [...]

garete: Esta voz marinesca, que la Academia limita a "las embarcaciones sin gobierno", en Cuba la aplicamos constantemente a los asun- 
tos terrestres "Familia al garete, colegio al garete, ingenio al garete". Aquí tenemos muchas cosas al garete. Hemos llegado a tener hasta el gobierno al garete, o sea un gobierno sin gobierno, que debe ser un colmo de... garete.

guasasa: El nombre de esa modestísima y diminuta mosca. [...] De paso recojamos una expresión criolla, no muy refinada que digamos, pero si muy expresiva, aplicada a las personas entrometidas e impertinentes. "Molesta como guasasa en culo de perro".

guerrita: Nombre que solemos dar a nuestras revoluciones armadas, o guerras civiles por su brevedad. "La guerrita de Febrero, la de Agosto”. Pero respetamos algo más la corta contienda separatista que siguió a la guerra nacional de los diez años, llamándola no guerrita, sino la "guerra chiquita".

morenaje: Conjunto de los morenos o negros: "todo el morenaje ingresó en el partido".

rabo: [...] Hoy se dice ponerle rabo como equivalente a reírse de uno. "Al presidente le pusieron rabo".

reales: Dinero. "Hombre de muchos reales". [...]

rosita: Decimos ir o estar de rositas al que va o está en condiciones muy ventajosas o preferentes. "Él fue a la lucha electoral sin gastar dinero, o sea, de rositas".

Los ejemplos utilizados por Ortiz son numerosos y se han dispuesto, por lo general -al menos en 15 de los casos identificados-a continuación de la definición, entrecomillados y son fruto de la inventiva del autor a no ser en el tratamiento del lema diablito en el que Ortiz se cita como autoridad y ofrece al lector de su singular repertorio de cubanismos abundante información sobre un tema que domina y sobre el cual acumula información valiosa. No puede sustraerse a citarse en extenso y a recomendar, incluso, la lectura de la obra en cuestión para proporcionar 
"minuciosas explicaciones". Un recurso, profusamente empleado por Ortiz, consiste en acudir a sus propias investigaciones. En especial, acude a los textos Glosario de afronegrismos (1924), Los instrumentos de la música afrocubana (1951) y Los bailes y el teatro de los negros en el folklore de Cuba (1951), piezas claves de su extraordinaria producción, que se tornan así fuentes directas del Nuevo Catauro... La información volcada en la entrada diablito contiene datos de esta naturaleza, por ejemplo.

En no pocos artículos lexicográficos, Ortiz ofrece ricas disquisiciones filológicas, antropológicas, etc. que llegan a confundir al investigador pues podría considerarse una modalidad de ejemplificación pero en una revisión cuidadosa se distinguen sus abundantes comentarios -que no contienen el lema en cuestión- de los ejemplos propiamente dichos que de forma bastante regular ha marcado con comillas para que resalten dentro del texto.

Aspectos de la realidad nacional tan diversos como la peculiaridad idiosincrática del cubano, sus tipos y costumbres (v. catedrático, guasasa) y no pocos rasgos específicos de la vida política del país, de sus mecanismos electorales y gubernamentales (v. forro, rabo y rosita); o referencias a la mujer y al sexo (v. caída, fajar) aparecen en el repertorio: todo ello matizado de fino humor y de un gracejo criollo que distingue todo el repertorio.

Juan Miguel Dihigo es el único lingüista entre los diccionaristas en estudio y su Léxico cubano (1928) contiene tal cúmulo de información de muy diverso carácter que cualquier búsqueda se torna compleja a pesar de que su recopilación impresa sólo abarcó las dos primeras letras del alfabeto. La obra publicada consta de dos volúmenes que abarcan respectivamente las letras A y B, así son de amplios y bien documentados sus artículos lexicográficos. Cada entrada contiene, además de las marcas gramaticales una definición que en muchos casos ha cotejado con otros autores cubanos así como un cuidadoso rastreo de su presencia en diccionarios de americanismos y de regionalismos.

En el Léxico cubano..., Juan Miguel Dihigo no emplea ejemplos. Su ideal lexicográfico es otro: apunta más al diccionario de americanismos, 
en la medida que rastrea los lemas seleccionados en las diversas obras del género en Cuba y en América y contrasta acepciones y usos (Camacho, en prensa). Al único filólogo entre los diccionaristas cubanos cuyas obras se han considerado en estas páginas, más bien le interesa recoger información normativa así como una exhaustiva recopilación acerca de la presencia de cada lema en los diccionarios de americanismos.

Tras las huellas del hombre y el reflejo de su tiempo nos adentraremos, entonces, en una pieza clave en la lexicografía cubana, el Léxico Mayor de Cuba (Tomos I y II), "tenida por muchos como el trabajo de mayor envergadura" (Alpízar, 1989: 156) publicado por Esteban Rodríguez Herrera entre 1958 y 1959. Un detallado estudio de este repertorio diferencial da cuenta de sus características (Camacho, 2003-2004).

En sus "Breves palabras al lector", Rodríguez Herrera advierte que su obra:

[...] Tiende [...] a suministrar a nuestro pueblo de cultura media en Cuba un cúmulo de vocablos que necesariamente debe conocer para enriquecer su lenguaje habitual, [...] (1958:VI).

En el Léxico Mayor..., este abogado de profesión se convierte en un innovador en cuanto a la incorporación regular y sistemática en su obra lexicográfica mayor de la ejemplificación, sobre todo a través de la citación de autoridades. Todas la citas han sido separadas de la definición en la microestructura y tratadas con tipografía distintiva, a saber, tamaño de letra menor y ordenados como sigue: contexto (ejemplo con el lema en cursiva) + autor (nombre y apellidos) + título de la obra.

\section{Veamos:}

batey. s.m. [...]

[...] delante había de estar el batey, gran plaza cuadrilonga, llana y siempre muy limpia; destinada al juego de batos (pelotas).

J.Ma . de la Torre, Robinson Cubano. 
Las autoridades citadas por Rodríguez Herrera se pueden encontrar ordenadas convenientemente en la bibliografía. Las fuentes son diversas. Proceden de textos literarios, tales como Cuadros de costumbres cubanas (1875), de Francisco de Paula Gelabert; de Rumores del hórmigo (1938), de Juan C. Nápoles Fajardo (El Cucalambé) y Cecilia Valdés (1839), de Cirilo Villaverde. También se han extraído de textos especializados en diversas materias, entre las cuales pueden mencionarse: Prontuario de Agricultura General (1856), de Antonio Bachiller y Morales; La caña de azúcar en Cuba (1946), de Fernando Agete y Piñero y Las aves de Cuba (1941), de Pelegrín Franganillo o de repertorios especializados como el Léxico tabacalero (1942), de José E. Perdomo. Así también Rodríguez Herrera ha incluido referencias tomadas de otros diccionarios diferenciales cubanos, de americanismos, de la lengua española general, así como enciclopedias y fuentes tan diversas y heterogéneas como la poesía, la música popular o los textos periodísticos, de tal manera que puede considerarse un precursor en la selección y manejo atinado de disímiles fuentes. Es el primer lexicógrafo cubano que utiliza de forma regular la ejemplificación como mecanismo para ilustrar y fijar el uso de una palabra o expresión. Entre sus contemporáneos despertó curiosidad y algunos valoraron su aporte, como queda expresado en el comentario del Profesor Quirino Francella: "Cierra una exhaustiva documentación en trozos sacados de escritores cubanos" (1959:662), entre otros comentarios elogiosos que aparecen reunidos en el volumen II del repertorio... bajo el epígrafe "Algunas referencias al Léxico Mayor de Cuba".

El autor no desdeña, por otra parte, la posibilidad de incluir ejemplos creados en lemas tales como ahuevado, ajilar, bombín, brisa, camayoa o chancleta, entre otros; pero su identificación y delimitación se torna difícil: estos quedan intercalados en el artículo lexicográfico y se pueden confundir con sus numerosos comentarios pues no ha empleado de forma sistemática las marcas tipográficas. En los artículos recurre a un mecanismo de identificación del lema en dichos comentarios, a través del uso de la letra cursiva y en algunos casos, como en brisa o chancleta recurre a la puntuación para diferenciar y separar la ilustración del uso de la definición propiamente dicha. Veamos: 
ahuevado: s.m. Manera indecorosa muy especial que emplean algunos bailadores, haciendo contorsiones lúbricas para provocar a la mujer. Puede practicar un hombre el ahuevado en el danzón, la rumba y hasta bailando solo. [...]

¡ajilar!: Exclamación usada en forma de mandato muy imperativo, principalmente en época de la esclavitud. Se ordenaba ajilar para que el esclavo se pusiera en fila o en hilera y pasarle revista diariamente. $[\ldots]$

bombín: s.m. [...] Actualmente se va abriendo paso a esta palabra para aplicar a las personas de calidad que van a los puestos públicos a título de competentes y no de meramente políticos. Estos les llaman bombines porque son hombres "de bombín", o sea "de altura”, desconocidos del elemento popular que vive de la política exclusivamente, en perjuicio de la buena administración pública.

brisa: s.f. Dícese fam. y festivamente por hambre o apetito: vamos a comer algo, lo que se encuentre, porque tengo una brisa. [...]

camayoa: s. m. Nombre indígena denigrativo con que designaban los indios del continente a los nativos que ejercían el oficio de pederastas pasivos, [...]. Por fortuna, sólo en la Tierra firme había camayoas, no en las islas del Caribe, [...]

chancleta: s. f. (la) fig. La chusma o gentualla. [...]. Se aplica a las personas en forma despectiva, por chancletero, ra: Por fin ¿quién ganó las elecciones el Partido Tal o el otro? - Ganó el de la chancleta. Ahora gobernará la chancleta y no la gente decente. [...]

Rodríguez Herrera alterna, incluso, las dos modalidades en estudio, como ocurre en:

aviado, da!: Interj. En las expresiones estar aviado, quedar aviado u otra análoga, equivale a estar lucido, arreglado, dicho esto irónicamente. ¿Sabes, mamá, que subieron el precio de los víveres? -¿Qué me 
dices? ¡Aviada estaría yo si eso resultara verdad! Fulano, ¿y si te dejan cesante? -Aviado estoy yo para una cesantía en estos momentos.

Cuando se los quitamos, entre los directivos, la guardia nacional y los ayudantes (que algo ayudaron) estaban los dos aviadores ¡bien aviados!

J. Aristigueta, ¡A L' Habana me voy! (Cuba) cap. XVII.

Argelio Santiesteban es uno de esos aficionados a recopilar palabras que consiguió reunir en las ediciones de su muy conocida Habla popular cubana de hoy, un abundante número de entradas léxicas. Son diversas las críticas que podrían formularse sobre los criterios de selección, la falta de sistematicidad, la perspectiva teórica errada, etc. En lo tocante al estilo de las definiciones intenta a toda costa ser ligero y desenfadado y utiliza una cuerda humorística que atenta en última instancia contra el producto lexicográfico.

En las dos ediciones publicadas de El Habla popular cubana de hoy, Argelio Santiesteban $(1985,1987)$ se ha valido de la ejemplificación con regularidad. En su extensa y valiosa recopilación de voces cubanas, la más completa después del Léxico..., de Rodríguez Herrera y la primera nacida en el período revolucionario - "el hecho cultural más genuino y grandioso de nuestra historia" - como lo califica su autor (1985), se utilizan amplia y eficazmente los ejemplos, bien sea como fruto de su inventiva o bien tomadas de diversas fuentes. Veamos algunos casos:

aguantón, na: Excesivamente tolerante.

Tiene rostro pacífico y hasta parece un poco aguantón.

(P. De la Torriente Brau, Aventuras del soldado desconocido cubano, 1936). [...]

arrollar: Bailar caminando al paso de la comparsa, según es característico en la conga. 
Qué mujer más descarada, como me la está pegando, mientras yo me rompo el cuero, ella en la rumba arrollando

(Tonada popular).

barra: Mostrador de un bar.

...Estás sentado en una barra...

(E. Álvarez Jané. Macuta La Habana, 1981).

berocos son claveles: (mis son claveles) Expresión con la cual se rechaza lo disparatado o falaz: "Si en Cuba no hace calor en agosto, mis berocos son claveles".

- ¿No es a ti a quién le dicen por ahí, la Duquesa?

- El mismo.

- Y ¿tú eres serio?

- Pues entonces mis berocos son claveles.

(C. Montenegro, Hombres sin mujer, 1937).

berro: Enfado, berrinche. [...]

No cojas berro, social.

(Del guión de la película cubana "Ustedes tienen la palabra").

El funerario cogió un berro grandisimo...

(S. Feijóo, Cuentos populares de humor, 1981).

bisne o birne: [...] Empresa amorosa: "hoy tengo un bisnecito con fulana". 
//Asunto de cualquier índole.

¿Y qué va a hacer con el dinero? ¿Va a plantar algún bisne?

(A. Molina, Los hombres color del silencio, 1975).

blanconazo, za: En la gradación de las razas, el mulato muy cercano al blanco.

Negros brillosos, negros rojizos, negros mulatos, mulatos, mulatos jabaos, mulatos blanconazos...

(E. Alvarez Jané, Macuta La Habana, 1981).

bola ( de humo): [...] Se aplica a toda persona relevante en cualquier aspecto. Sea este positivo o negativo.

Es una bola de humo

que saca de quicio a cualquiera...

(Canción popular).

material: Mujer desde el punto de vista de la relación erótica.

Es común el diminutivo: "en este barrio tengo un materialito".

planchá: Se dice que lo está o que lo es, la mujer desprovista de convexidades, ya sean las pectorales o las glúteas. ¡Gravísima deformidad, según nuestros cánones estéticos! [...]

"delgada y angulosa con el busto planchado, al igual que la grupa...".

(E. Serpa, Felicia y yo, 1925).

tipo, pa: Tipejo, sujeto. La Academia ignora el femenino tipa, tan usado entre nosotros como despectivo. Véase un ejemplo de su utilización entre nosotros: 


\title{
¿qué se figuraba aquella tipa? ¿que él iba a dejar que lo explotara?
}

\author{
(J. Soler Puig, El derrumbe, 1964).
}

Santiesteban recrea en numerosos ejemplos el uso de las palabras a partir de su inventiva y de forma alternativa añade además los tomados de autoridades; tanto los primeros como estos últimos son identificados y distinguidos de forma sistemática. Los ejemplos creados aparecen entre plecas, a continuación de la definición, sin separación como párrafo aparte. En cuanto a los procedimientos de citación ha seguido con regularidad el mecanismo de separar en párrafo francés el texto ilustrativo y a renglón seguido registra los datos de las autoridades correspondientes (autor, título de la obra y año, todo entre paréntesis). Al seguir ambos procedimientos, se ha cuidado de marcar todo el ejemplo en un tipo de letra más pequeña que el texto definicional, lo marca en redonda y distingue el lema en cursiva.

Las fuentes nutricias son ricas y diversas. La literatura cubana constituye reservorio de abundantes contextos que aportan a la obra: escritores de "ayer", como Cirilo Villaverde (1812-1894), Diego Vicente Tejera (1885. 1945), la Condesa de Merlín (1789-1852), José Jacinto Milanés (18141863), Manuel de la Cruz (1861-1896) y el propio José Martí (1853-1895) y escritores de "hoy" como Lisandro Otero (1932-2007), Alejo Carpentier (1904-1980), Ramiro Guerra (1880-1970), Manuel Moreno Fraginals (19202001), Samuel Feijóo (1914-1992), Onelio Jorge Cardoso (1914-1986), entre otros tantos grandes de nuestras letras. Se ha servido además, como era de esperar, de las recopilaciones de voces anteriores, las que le suscitan todo género de comentario, así cita a Pichardo, a Suárez, a Ortiz, a Rodríguez Herrera. Además, ha tomado en consideración repertorios menos conocidos o restringidos a alguna región, tales como el Anagó. Vocabulario lucumí (1957), de Lydia Cabrera, el Vocabulario espirituano (1928), de J. Martínez-Moles o el Oriente folklórico (1934), de Ramón Martínez. Asimismo, este "recolector" -como se denomina en las palabras introductorias a la primera edición de El habla... (1985:22) - se ha valido de otras fuentes de las que hace un uso inteligente y eficaz: discursos, textos periodísticos, cancionero popular, trova tradicional o guiones de películas cubanas. 
Comentario aparte merece el uso como ejemplos de acepciones y contextos extraídos de los clásicos de la literatura española: así encontramos referencias a Bartolomé de las Casas, López de Gomara, Luis de Góngora o Benito Pérez Galdós, entre otros muchos. Entre las diferentes observaciones críticas que ha recibido esta obra viene a sumarse esta desacertada ilustración del uso con ejemplos de la literatura española en un repertorio que selecciona su material fáctico del "habla popular cubana de hoy”, título que engloba criterios diastráticos, diafásicos, diferenciales y sincrónicos polémicos por sí mismos. En un intento de historiar la vida de las palabras y su condición patrimonial recurre, entonces, a la ejemplificación con textos que no son adecuados.

El repertorio contiene definiciones redactadas en un tono que quiere ser ligero y desenfadado. El autor acumula comentarios de toda índole, resultado de sus búsquedas, expresión también de su competencia lingüística, pero que además se encuentran cargados de subjetividad y valoraciones de tipo personal. Los ejemplos no quedan exentos de tal carga subjetiva y si se observa, a manera de muestra, en algunos de los casos expuestos arriba (v. material, planchá, tipa) sobresale una mirada androcéntrica, machista, vulgar y hasta ofensiva: no son ingenuos sino voluntariamente elegidos y llevados como fragmentos de vida, como trozos de la lengua en Cuba a las páginas de un repertorio de palabras de gran repercusión entre un público en general y entre especialistas de la lengua.

A manera de resumen puede concluirse que tanto Pichardo como Suárez hacen un uso irregular, asistemático e infrecuente de los ejemplos, pero que éstos vehiculan, como pudo demostrarse en el análisis de la muestra el componente ideológico que rastreamos. Dihigo, nuestro único lingüista en esta hornada de diccionaristas, no recurre al ejemplo, sobre todo porque su propósito es otro. La obra orticiana se nos presenta como de transición hasta la aparición del Léxico Mayor... que se puede identificar entonces como la gran innovadora en cuanto al empleo de las citas y de los ejemplos - no exentos de matices subjetivos-. Su peculiaridad reside sobre todo en la ejemplificación extraída de las fuentes literarias. Santiesteban, heredero de una tradición lexicográfica sistematiza el uso de 
la ejemplificación y la enriquece, en particular por la diversificación de las fuentes nutricias y su tratamiento tipográfico estable y coherente, y es por otra parte, el autor que de forma sutil o explícita deja brotar su ideología de forma descontrolada y con regularidad en todo el repertorio.

Sin lugar a dudas la muestra seleccionada se corresponde con un estadio de desarrollo anterior al empleo de los corpus y de las bases de datos en la lexicografía contemporánea. Como advierte López Morales, en su meridiana historia La aventura del español en América (1998:129):

Hace tan solo unos años bastaba con que la palabra hubiese sido empleada por un escritor de renombre, a pesar de sus constantes revisiones, el DRAE trae todavía ejemplos de americanismos que solo figuran en sus páginas por el prestigio que les ha conferido algún escritor de talla, cuya autoridad en materia idiomática se ha llegado a imponer. Aunque aún queda mucho camino por delante, el criterio de autoridad cede espacio al de frecuencia de uso.

\section{BIBLIOGRAFÍA}

ALPIZAR, R. Apuntes para la historia de la lingüística en Cuba. La Habana, Ed. Ciencias Sociales, 1989.

ALVAR EZQUERRA, Manuel. Lexicografía descriptiva. Barcelona, Bibliograf, 1993.

BAJO, Elena. Diccionarios. Introducción a la historia de la lexicografía del español. Guijón, Ediciones Trea, 2000, separata, pp. 48-51.

BARGALLÓ, María. "Sobrela función sintagmática del ejemplo lexicográfico", en PÉREZ PASCUAL, José Ignacio y CAMPOS SOUTO, Mar (eds.). Cuestiones de lexicografía. Lugo, Tris Tram, 2002.

"El tratamiento metalingüístico del ejemplo en los diccionarios monolingües del español”, en CAMPOS SOUTO, 
Mar, CONDE NOGUEROL, Eugenia, PÉREZ PASCUAL, José Ignacio, PORTO DAPENA, José Álvaro (coord.). Reflexiones sobre el diccionario. Universidade da Coruña, Servicio de Publicaciones, 2007, separata, pp. 139-150.

CAMACHO BARREIRO, Aurora M. "Fernando Ortiz, lexicógrafo", en Montalbán. Revista de La Universidad Católica Andrés Bello, 33, 2000, pp. 269-278.

. "Huellas ideológicas en la lexicografía cubana", en Revista de lexicografía. Universidade da Coruña, X, 2003-2004, pp.21-38.

. "Diccionario e ideología: el Léxico Mayor de Cuba de Esteban Rodríguez Herrera”, en ALEZA IZQUIERDO, Milagros, SANMARTIN, Julia (coord). Estudios de lexicografía y léxico cubanos. Universidad de Valencia, 2004, pp. 11-35.

FORGAS, Esther. "La imagen social de la mujer en tres décadas de ejemplos lexicográficos", en Panorama actual de la lingüística aplicada. Conocimiento, procesamiento y uso del lenguaje. Logroño, Mogar, 2000, separata, pp. 1021-1030.

. "Diccionario e ideología: tres décadas de la sociedad española a través de los ejemplos lexicográficos", en Espéculo. Revista Electrónica Cuatrimestral de Estudios Literarios. Universidad Complutense de Madrid, 2004, separata, $14 \mathrm{p}$.

LLEDÖ CUNILL, Eulália. "Los ejemplos", en CALERO FERNÁNDEZ, María Angeles, FORGAS BERDET, Esther, LLEDÓ CUNILL, Eulália (coord.). De mujeres y diccionarios: evolución de lo femenino en la 22a edición del DRAE. Madrid, Ministerio de Trabajo y Asuntos Sociales, Instituto de la Mujer, 2004, pp. 23-96.

LÓPEZ MORALES, H. La aventura del español en América. Madrid, Espasa Calpe, S.A., 1998.

PORTO DAPENA, José Álvaro. Manual de técnica lexicográfica. Madrid, Arco Libros, S.A., 2002, 367 p. 
VALADEZ, Carmen D. "El papel de los ejemplos en el Diccionario del Español Usual en México", en PÉREZ PASCUAL, José Ignacio, CÓRDOBA RODRÍGUEZ, Félix, CAMPOS SOUTO, Mar (eds.). América y el diccionario. Anexos de Revista de Lexicografía, 2, Universidade da Coruña, Servicio de Publicaciones, 2006, pp. 153-163.

\section{Correspondencia:}

Aurora M. Camacho Barreiro

Correo electrónico: niurkaruiz@infomed.sld.cu 
